\title{
Photocontrol of Polypeptide Membrane Functions by Photo- dissociation of Pararosaniline Side-Chain Groups
}

\author{
Morimasa SATO, Takatoshi Kinoshita, Akira TAKIZAWA, \\ and Yoshiharu TsuJiTA \\ Department of Materials Science \& Engineering, Nagoya Institute of Technology, \\ Gokiso-cho, Showa-ku, Nagoya 466, Japan
}

(Received March 24, 1988)

\begin{abstract}
A photoresponsive polypeptide membrane composed of poly(L-glutamic acid) (PGA) with $15.5 \mathrm{~mol} \%$ pararosaniline (rose) groups in the side chains (rose-PGA) were prepared. The rose side chains in the membrane exhibited photodissociation under ultraviolet (UV) light irradiation, yielded hydroxide ions, which resulted in the acceleration of acid dissociation of the neighboring L-glutamic acid moieties. This increase in the dissociation of L-glutamic acid moieties induced the conformational transitions of the rose-PGA membrane at adequate pHs. As a result, the membrane functions of the rose-PGA, such as transport properties and membrane potentials across the membrane, were strongly dependent on UV light irradiation. The photoinduced changes of the membrane functions of the rose-PGA were reversible and synchronized with the conformational responses of the membrane under UV light irradiation.

KEY WORDS Photoresponsive Polypeptide Membrane / Pararosaniline

Side Chain / Poly(L-glutamic acid) / Photoinduced Conformational Change

/ Photoinduced Membrane Potential Change / Photoinduced Permeability

Change /
\end{abstract}

The photocontrol of polymer membrane functions, such as transport properties and membrane potentials, has been attracting attention in membrane science and thechnology in view of its significance as a biomimetic system of the photo-receptor and its potential for a foregoing information-transfer technique.

It has been shown that artificial photoresponsive polymer membranes can be simply made by entrapping photochromic groups, such as azobenzene, ${ }^{1,2}$ spirobenzopyran ${ }^{3-7}$ and others ${ }^{8,9}$ into the membrane matrix. However, there are few studies ${ }^{10-12}$ on photoinduced effects of the functions of membranes containing photochromic groups incorporated as pendant groups in polymer chains.

In previous studies, ${ }^{13-15}$ we reported the photocontrol of transport properties and membrane potentials of polypeptide membranes composed of poly(L-glutamic acid)
(PGA) containing azobenzene groups in the side chains based on cooperative effects between the photo-isomerization of the azobenzene group and induced acid dissociation of neighboring glutamic acid moieties in the membranes. Recently, we also investigated the photoinduced conformational transitions of a polypeptide membrane composed of PGA with pararosaniline (rose) in the side chains (rose-PGA). ${ }^{16,17}$ It was found that ultraviolet (UV) light irradiation was associated with increase in hydroxide ion concentration in the membrane phase via photodissociation of the rose moieties and initiated acid dissociation of the neighboring glutamic acid groups, resulting in conformational response of the membrane.

We report here the photocontrol of transport properties and membrane potentials across a rose-PGA membrane based on con- 
formational changes of the membrane under UV light irradiation.

\section{EXPERIMENTAL}

\section{Materials}

Poly(L-glutamic acid) (PGA) was obtained by saponifying poly( $\gamma$-methyl L-glutamate) (PMG) in a mixture of methyl alcohol, isopropyl alcohol and $1.2 \mathrm{~mol} \mathrm{dm}^{-3}$ aqueous solution of $\mathrm{NaOH}$ in the volume ratio of $2: 2: 1$ at $20^{\circ} \mathrm{C}$. The PMG was kindly provided by Ajinomoto Co., Ltd. The molecular weight of PGA obtained was $1.19 \times 10^{5}$ by viscosity measurement of an aqueous solution of PGA containing $1.0 \mathrm{~mol} \mathrm{dm}^{-3} \mathrm{NaCl}$. PGA having pararosaniline groups (rose-PGA) was synthesized by the coupling reaction between PGA and pararosaniline (rose) in dimethylformamide (DMF) solution with $N$-hydroxybenzotiazole (HOBt) and 1-ethyl-3,3-dimethylaminopropylcarbodiimide hydrochroride $(\mathrm{EDC} \cdot \mathrm{HCl})$. The synthesis of rose-PGA has been described in detail previously. ${ }^{17}$ The $\mathrm{mol} \%$ of the rose moieties in the polymer was estimated to be $15.5 \mathrm{~mol} \%$ from absorbance at $\lambda_{\max }=560 \mathrm{~nm}$ of the rose-PGA in DMF solution, on the basis of the molar extinction coefficient of the model compound, 4-propioamide- $4^{\prime}, 4^{\prime \prime}$-diamino-triphenyl carbinol, at $560 \mathrm{~nm}$.

The rose-PGA membrane was prepared by casting from a solution of $c a .2 \mathrm{wt} \%$ in DMF with $\mathrm{HOBt}$ and $\mathrm{EDC} \cdot \mathrm{HCl}$ at $40^{\circ} \mathrm{C}$. The membrane of $c a .2-3 \mu \mathrm{m}$ in thickness obtained was repeatedly washed with methyl alcohol. The insoluble charactor of the rose-PGA membrane to alkaline water and DMF suggests that networks of loosely crosslinked polymers were formed in the membrane by the residual amino groups in the rose moiety during the casting process.

\section{Measurements}

Absorption and circular dichroism (CD) spectra of the membranes in aqueous solution were recorded on a JASCO UVIDEC 670 spectrophotometer and JASCO J-40C spectropolarimeter, respectively. The molar ellipticity, $[\theta]$, of the membrane was calulated by following equation.

$$
[\theta]=\frac{\theta \times M_{w}}{d \times l}
$$

where $\theta, M_{w}, d$, and $l$ are ellipticity, average residual molecular weight, density of the membrane and membrane thickness, respectively.

Infrared (IR) spectra of the membrane was measured with a infrared spectrometer (JASCO IR-700). The measurements were carried out using a water containing membrane, adapted in the dark or irradiated. Owing to the strong absorption of water in the membrane, reliable data of the spectra associated with the membrane matrix were limited to ranges from 1760 to $1710 \mathrm{~cm}^{-1}$ and 1470 to $1420 \mathrm{~cm}^{-1}$, respectively.

The degree of hydration of the membrane, $H$, weight fraction of water in the waterswollen membrane, was determined at $25^{\circ} \mathrm{C}$. The membrane was allowed to swell in the dark and UV irradiation, respectively, blotted and weighed until constant weight was obtained, and then dried under reduced pressure. The $H$ value was calculated from the difference of the weights.

Measurement of the permeation of styrene glycol through a membrane was carried out by using permeation cell at $25^{\circ} \mathrm{C}$. A $1.0 \mathrm{moldm}^{-3}$. aqueous solution of styrene glycol was introduced into one side of the cell and a solute free solution was introduced into the other side (permeated side) of the cell. Solutions of the permeated side were taken out after given periods of time and then UV absorbance at $256.8 \mathrm{~nm}$ associated with the styrene glycol was measured to determine the degree of permeation through the membrane. The cell circuit for the determination of membrane potentials, $(\Delta(\Delta \psi))$, is represented by

Polymer J., Vol. 20, No. 9, 1988 


\author{
$\mathrm{Ag} \cdot \mathrm{AgCl} \mid$ sat. $\mathrm{KCl}\left|c_{1}\right|$ \\ 1 \\ membrane $\left|c_{2}\right|$ sat. $\mathrm{KCl} \mid \mathrm{Ag} \cdot \mathrm{AgCl}$ \\ 2
}

where $\mathrm{Ag} \cdot \mathrm{AgCl}$ is $\mathrm{Ag} \cdot \mathrm{AgCl}$ electrode and junctions 1 and 2 were connected by salt bridges. In this case, $c_{1}$ and $c_{2}\left(c_{1}>c_{2}\right)$ are the $\mathrm{KCl}$ concentrations, and the potential of the higher $\mathrm{KCl}$ concentration $\left(c_{1}\right)$ side was taken as zero. The $\mathrm{KCl}$ concentration ratio, $c_{1} / c_{2}$, was fixed at 10 . Membrane potential measurements were performed at $25^{\circ} \mathrm{C}$.

Irradiation of the membrane was carried out with a 500W super-high-pressure mercury lamp (Ushio UVD 500) equipped with a Toshiba UV-D33s filter for UV light irradiation $(250 \mathrm{~nm}<\lambda<380 \mathrm{~nm})$.

\section{RESULTS AND DISCUSSION}

\section{Photoinduced Conformational Transition of the}

\section{Rose-PGA Membrane}

Rose-PGA is an amphoteric polypeptide, since the glutamic acid side chains are neg-

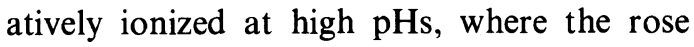
moieties, whose $\mathrm{p} K_{\mathrm{a}}$ is $7.6,{ }^{17}$ are positively ionized at low pHs. As a result, rose-PGA with $15.5 \mathrm{~mol} \%$ rose groups exhibited an unique $\mathrm{pH}$ dependence of the backbone structure. ${ }^{17}$ That is, rose-PGA was in a random coil conformation at low ( $<\mathrm{pH} 7.5)$ and high $(>\mathrm{pH} 10.5)$ $\mathrm{pHs}$ where the repulsion forces among these charged side chains of the same sign are predominate under the two different $\mathrm{pH}$ conditions, respectively. On the other hand, the polymer could form an $\alpha$-helix structure in a narrow $\mathrm{pH}$ region around a weak alkaline $(7.5<\mathrm{pH}<10.5)$, where these charged side chains neutralized each other.

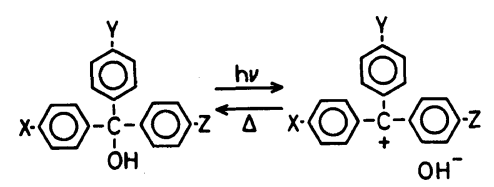

Scheme I.
Furthermore, it has been shown that triarylmethane leucohydroxide can be dissociated not by neutralization with proton ions in acid solution but also by photodissociation with UV light irradiation (Scheme I) ${ }^{18}$. Figure 1(a) shows the changes of the absorption band at $560 \mathrm{~nm}$ in the UV-visible spectra of the rose-PGA membrane containing $15.5 \mathrm{~mol} \%$ rose moieties at $\mathrm{pH}$ 8.6. UV irradiation was found to increase the absorption band at $560 \mathrm{~nm}$ which is associated with the triarylmethyl cations of the rose moieties. This suggests that the partially ionized rose moieties of the rose-PGA membrane in the aqueous solution of $\mathrm{pH} 8.6$ can be further dissociated by irradiation, in a similar manner as the low molecular weight leuco dye, and yield hydroxide ions inside the membrane. It was also found that the absorption band at $560 \mathrm{~nm}$ completely returned to the original value for $100 \mathrm{~min}$ in the dark at $25^{\circ} \mathrm{C}$ (Figure 1(a)). Therefore, $\mathrm{pH}$ in the membrane can possibly be controlled by irradiation and dark adaptation.

Moreover, IR spectra of the water-containing rose-PGA membrane with $15.5 \mathrm{~mol} \%$ rose groups adapted in the dark or irradiated at $\mathrm{pH} 8.6$ are shown in Figure 2. The difference between the two states is observed in absorption bands at $1730 \mathrm{~cm}^{-1}$ in Figure 2(a) and $1440 \mathrm{~cm}^{-1}$ in Figure 2(b). The $\mathrm{C}=\mathrm{O}$ ester group in the glutamic acid side chain gives the band at $1730 \mathrm{~cm}^{-1}$ in the carbonyl streching region in Figure 2(a). On the other hand, the absorption band at $1440 \mathrm{~cm}^{-1}$ in Figure 2(b) is attributable to the symmetric $\mathrm{C}_{-}-\mathrm{O}$ stretching mode of the dissociated $\mathrm{COO}^{-}$group of the glutamic acid moiety. It is confirmed, therefore, that irradiation produces an increase in the degree of dissociation of glutamic acid.

Figure 1(b) shows the photoinduced conformational transition of the membrane composed of rose-PGA with $15.5 \mathrm{~mol} \%$ rose groups. UV irradiation was carried out at $\mathrm{pH}$ 8.6 , coil to helix transition point of the polymer, where the random coil confromation is 

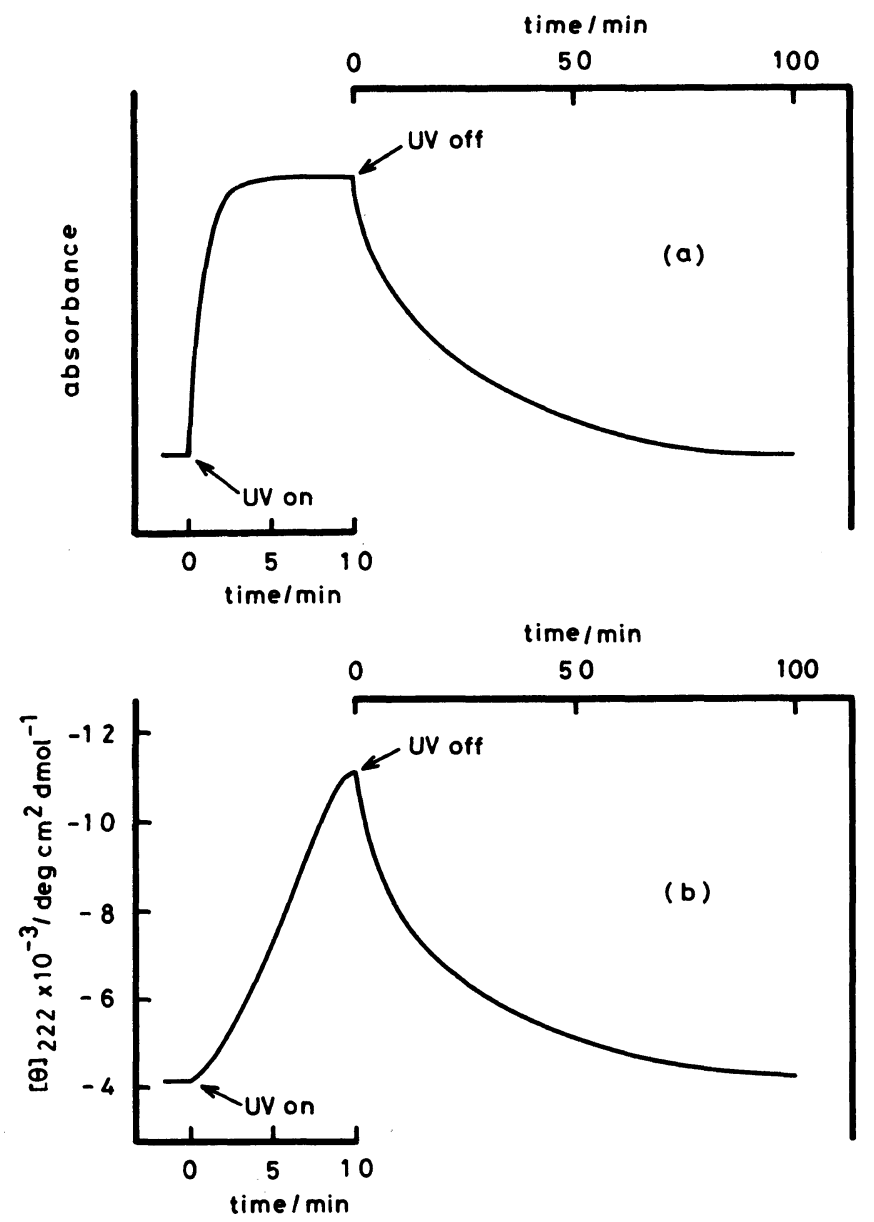

Figure 1. (a) Changes in absorbance at $560 \mathrm{~nm}$ of a membrane composed of poly(L-glutamic acid) containing $15.5 \mathrm{~mol} \%$ pararosaniline groups upon ultraviolet light irradiation and dark adaptation in aqueous solution at $\mathrm{pH} 8.6$ and at $25^{\circ} \mathrm{C}$; (b) changes in the molar ellipticity at $222 \mathrm{~nm},[\theta]_{222}$, of a membrane composed of poly(L-glutamic acid) containing $15.5 \mathrm{~mol} \%$ pararosaniline groups in aqueous solution on ultraviolet light irradiation and dark adaptation in aqueous solution at $\mathrm{pH} 8.6$ and at $25^{\circ} \mathrm{C}$.

predominate in the rose-PGA owing to the electostatic repulsion among the partially ionized rose moieties. It was found that the rosePGA membrane exihibited conformational response to light at $\mathrm{pH} 8.6$, the molar ellipticity at $222 \mathrm{~nm},[\theta]_{222}$, being decreased from $-4.08 \times 10^{3} \mathrm{deg} \cdot \mathrm{cm}^{2} \cdot \mathrm{dmol}^{-1}$ to $-1.10 \times 10^{4}$ $\mathrm{deg} \cdot \mathrm{cm}^{2} \cdot \mathrm{dmol}^{-1}$ in $c a .10 \mathrm{~min}$. This photoinduced formation of $\alpha$-helix structure may be explained from the fact that the acid dissociation of the glutamic acid groups on photoinduced $\mathrm{pH}$ increase (Figure 2) com- pensates for the repulsion among the positively ionized rose moieties (Scheme II).

It was also shown that dark adaptation increased the molar ellipticity, $[\theta]_{222}$, to be original value for $c a .100 \mathrm{~min}$, thus confirming the reversibility of the change (Figure 1(b)). Moreover, photoinduced conformational changes of the membrane (Figure 1(b)) were almost consistent with the absorbance changes at $560 \mathrm{~nm}$ in Figure 1(a). However, the helix formation was shown to respond more slowly than the absorbance increase. 


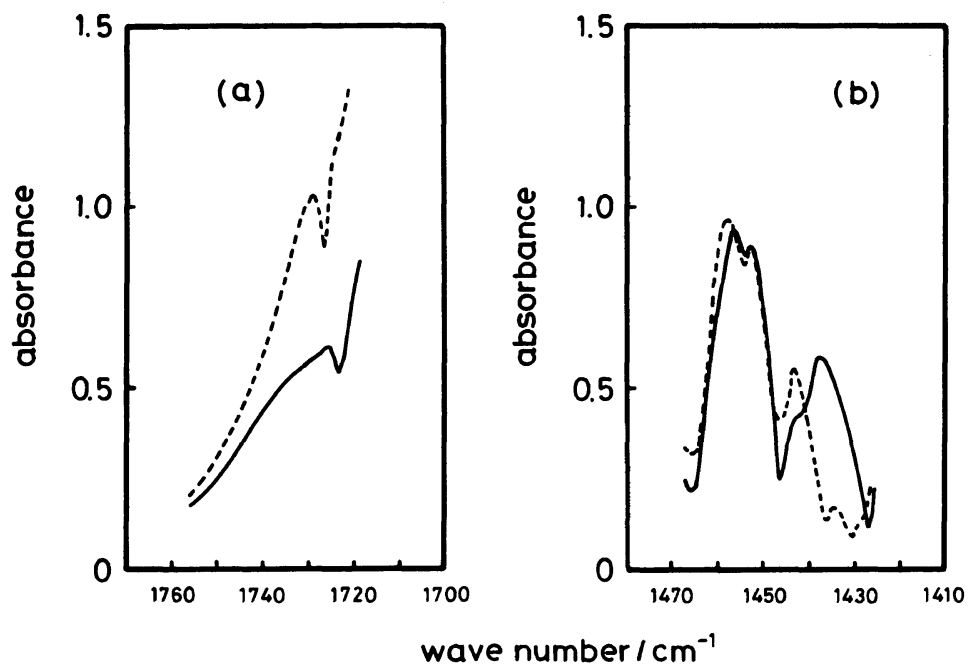

Figure 2. Infrared spectra of a water-swollen membrane composed of poly(L-glutamic acid) containing $15.5 \mathrm{~mol} \%$ pararosaniline groups at $\mathrm{pH} 8.6$ and at $25^{\circ} \mathrm{C}:(---)$ in the dark and (-) on ultraviolet light irradiation for $10 \mathrm{~min}$.

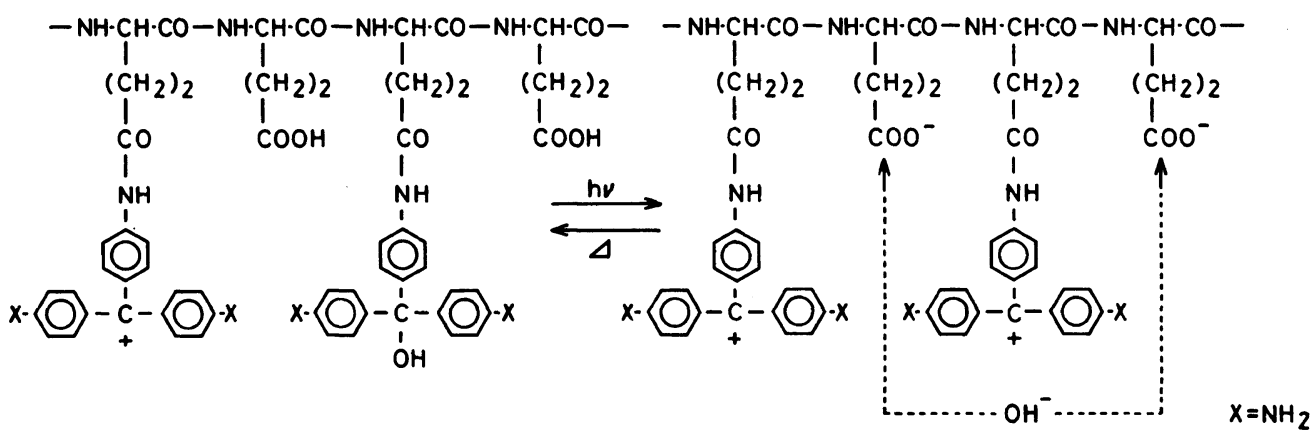

Scheme II.

To elucidate the lag of the helix formation at $\mathrm{pH} \mathrm{8.6,} \mathrm{the} \mathrm{photoinduced} \mathrm{conformational}$ change of the rose-PGA membrane was assumed to be a series first-order reactions ${ }^{19}$ with corresponding rate constants, $k_{1}, k_{2}$, and $k_{3}$, as follows.

$$
\mathrm{A} \stackrel{k_{1}}{\longrightarrow} \mathrm{B} \stackrel{k_{2}}{\longrightarrow} \mathrm{C} \stackrel{k_{3}}{\longrightarrow} \mathrm{D}
$$

A : Rose-PGA is predominantly in the random coil conformation at $\mathrm{pH} 8.6$ in the dark, in which the rose moieties are partially ionized $\left(-(\mathrm{Ph})_{3} \mathrm{C}^{+},-(\mathrm{Ph})_{3} \mathrm{COH}\right)$ and the L-glutamic acid moieties are undissociated $(-\mathrm{COOH})$.

B : UV irradiation is applied to the membrane. Ion pairs, $(-\mathrm{Ph})_{3} \mathrm{C}^{+} \cdot \mathrm{OH}^{-}$, are immediately produced on the rose moieties by irradiation.

C: Rose-PGA is in the transition state just before the conformational change occures. Intra-membrane diffusion of $\mathrm{OH}^{-}$accelerates the dissociation of the neighboring glutamic acid groups $\left(-\mathrm{COO}^{-}\right)$to a critical degree; however, the polymer keeps the random coil structure by cooperativity of 
the conformational change.

D: Rose-PGA froms $\alpha$-helix structure by neutralization between the cationic rose moieties and dissociated L-glutamic acid groups.

The rate equations, $-\mathrm{d}[\mathrm{A}] / \mathrm{d} t=k_{1}[\mathrm{~A}]$, $-\mathrm{d}[\mathrm{B}] / \mathrm{d} t=k_{2}[\mathrm{~B}]-k_{1}[\mathrm{~A}], \quad-\mathrm{d}[\mathrm{C}] / \mathrm{d} t=k_{3}[\mathrm{C}]-$ $k_{2}[\mathrm{~B}]$, and $\mathrm{d}[\mathrm{D}] / \mathrm{d} t=k_{3}[\mathrm{C}]$ intagrate to

$$
\begin{aligned}
{[\mathrm{A}]=} & A_{0} \mathrm{e}^{-k_{1} t} \\
{[\mathrm{~B}]=} & \frac{A_{0} k_{1}}{k_{2}-k_{1}}\left(\mathrm{e}^{-k_{1} t}-\mathrm{e}^{-k_{2} t}\right) \\
{[\mathrm{C}]=} & \frac{A_{0} k_{1} k_{2}}{k_{2}-k_{1}}\left\{\frac{1}{k_{3}-k_{1}} \mathrm{e}^{-k_{1} t}-\frac{1}{k_{3}-k_{2}} \mathrm{e}^{-k_{2} t}\right. \\
& \left.-\left(\frac{1}{k_{3}-k_{1}}-\frac{1}{k_{3}-k_{2}}\right) \mathrm{e}^{-k_{3} t}\right\} \\
{[\mathrm{D}]=} & A_{0}-\left[A_{0} \mathrm{e}^{-k_{1} t}+\frac{A_{0} k_{1}}{k_{2}-k_{1}}\left(\mathrm{e}^{-k_{1} t}-\mathrm{e}^{-k_{2} t}\right)\right. \\
+ & \frac{A_{0} k_{1} k_{2}}{k_{2}-k_{1}}\left\{\frac{1}{k_{3}-k_{1}} \mathrm{e}^{-k_{1} t}-\frac{1}{k_{3}-k_{2}} \mathrm{e}^{-k_{2} t}\right. \\
& \left.\left.-\left(\frac{1}{k_{3}-k_{1}}-\frac{1}{k_{3}-k_{2}}\right) \mathrm{e}^{-k_{3} t}\right\}\right]
\end{aligned}
$$

$$
A_{0}=[\mathrm{A}]+[\mathrm{B}]+[\mathrm{C}]+[\mathrm{D}](\text { at a given time } t)
$$

where $[\mathrm{A}],[\mathrm{B}],[\mathrm{C}]$, and $[\mathrm{D}]$ are the concentrations of the rose-PGA shown below.

[A]: Concentration of rose-PGA in the random coil structure containing partially ionized rose moieties and undissociated Lglutamic acid moieties. [A] equals to $A_{0}$ at $t=0$.

[B]: Concentration of rose-PGA in the random coil structure containing photodissociated rose moieties carrying ion pairs of $-(\mathrm{Ph})_{3}$ $\mathrm{C}^{+}$and $\mathrm{OH}^{-}$and undissociated $\mathrm{L}-$ glutamic acid moieties.

$[\mathrm{C}]$ : Concentration of rose-PGA in the random coil structure containing dissociated rose moieties and partially dissociated Lglutamic acid moieties.

[D]: Concentration of rose-PGA mainly in the $\alpha$ - helix structure containing dissociated
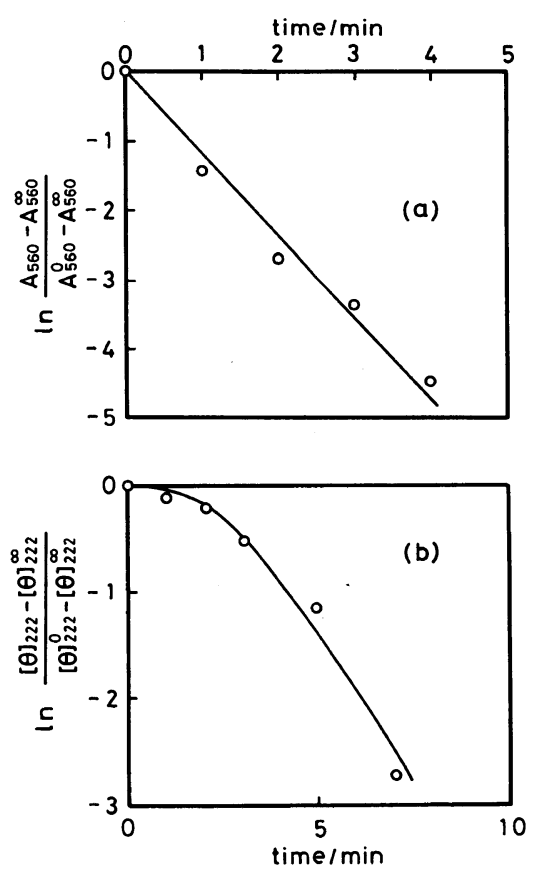

Figure 3. (a) First-order plot of the photodissociation of pararosaniline groups in the side chain; (b) analysis of the photoinduced conformational transition of poly(Lglutamic acid) containing $15.5 \mathrm{~mol} \%$ pararosaniline groups in a membrane in a series first-order reaction. (-O-), experimental data; (-), calculated value from eq 4 , with $k_{1}=1.16 \mathrm{~min}^{-1}, k_{2}=0.42 \mathrm{~min}^{-1}$, and $k_{3}=0.43 \mathrm{~min}^{-1}$.

rose moieties and partially dissociated $\mathrm{L}$ glutamic acid moieties. [D] equals to $A_{0}$ at $t=\infty$.

Figure 3(a) and (b) show the time dependence of the two parameters, $\ln \left(\left(A_{560}-\right.\right.$ $\left.\left.A_{560}^{\infty}\right) /\left(A_{560}^{0}-A_{560}^{\infty}\right)\right)$ and $\ln \left(\left([\theta]_{222}-[\theta]_{222}^{\infty}\right) /\right.$ $\left.[\theta]_{222}^{0}-[\theta]_{222}^{\infty}\right)$, respectively. $A_{560}$ is the absorption intensity at $560 \mathrm{~nm}$ of the rose-PGA membrane at $\mathrm{pH} 8.6$ and the subscripts 0 and $\infty$ mean $t=0$ and $t=\infty$, respectively. The rate constant, $k_{1}$, was estimated to be $1.16 \mathrm{~min}^{-1}$ by applying eq 1 to the experimental data in Figure 3(a). Then, application of eq 4 to the experimental data of the conformational kinetics in Figure 3(b) using the non-linear least squeares method and $k_{1}=1.16 \mathrm{~min}^{-1}$ yielded $k_{2}=0.42 \mathrm{~min}^{-1}$ and $k_{3}=0.43 \mathrm{~min}^{-1}$. The calculated [D] of eq 4 


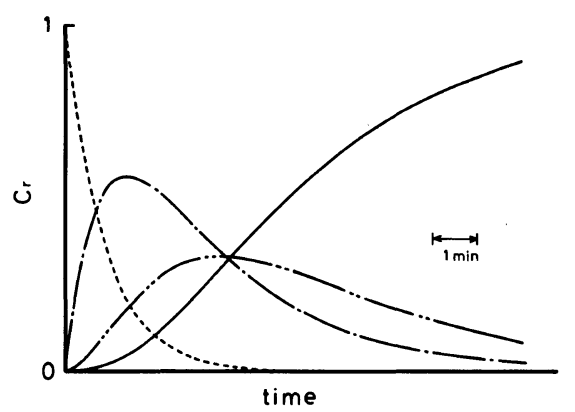

Figure 4. Time dependence of reduced concentration, $C_{\mathrm{r}}$, for [A], (---); [B], (---); [C], (-.- - ; and [D], ( $\left(\right.$ ) calculated from eq $1-4$ with $k_{1}=1.16 \mathrm{~min}^{-1}$, $k_{2}=0.42 \mathrm{~min}^{-1}$, and $k_{3}=0.43 \mathrm{~min}^{-1}$.

with $k_{1}, k_{2}$, and $k_{3}$ obtained is shown by the solid line in Figure 3(b). Good agreement between the calculated values of eq 4 and experimental data was obtained. Moreover, the variation in concentrations of the rosePGA, [A], [B], [C], and [D], can be expressed by eq $1,2,3$, and 4 , respectively, with the rate constants thus obtained. The results are shown by the reduced concentration $[\mathrm{A}] / A_{0}$ to $[\mathrm{D}] / A_{0}$ in Figure 4. It is clear that the rate of the helix formation, the variation of $[\mathrm{D}] / A_{0}$, was slow at the initial portion of the transition process. It is also seen that this induction period is attributable to the time required from the intermediate reaction $\mathrm{B} \rightarrow \mathrm{C}$. Thus, the lag in the conformational response in Figure 1(b) can be ascribed to two factors. One is the intramembrane diffusion process of hydroxide ions, i.e., the time taken to reach an equilibrium distribution of the hydroxide ions, yielded by the photodissociation of the rose moiety, in the membrane. The other is the cooperative behavior of the conformational change of the rose-PGA.

\section{Photoinduced Membrane Potential Change of the Rose-PGA Membrane}

The changes in the membrane potential, $\Delta(\Delta \psi)$, of the rose-PGA membrane containing $15.5 \mathrm{~mol} \%$ rose groups on UV irradiation was observed with a $\mathrm{KCl}$ concentration gradient of $c_{1} / c_{2}=10$ at $25^{\circ} \mathrm{C}$. UV irradiation was carried

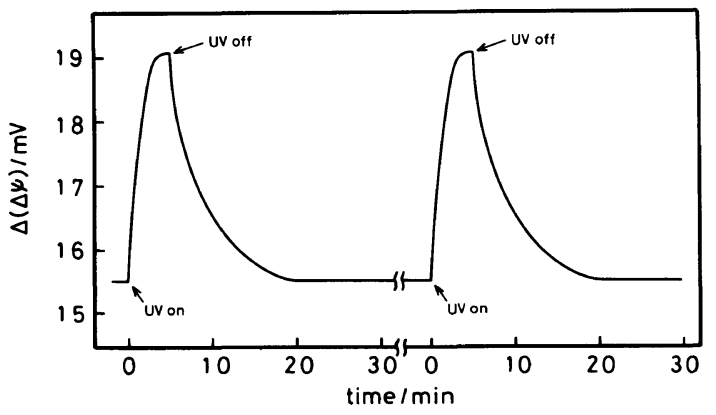

Figure 5. Changes in membrane potential of a membrane composed of poly(L-glutamic acid) containing $15.5 \mathrm{~mol} \%$ pararosaniline groups at $c_{1}=1.0 \times 10^{-2}$ mol dm ${ }^{-3}$ and $c_{2}=1.0 \times 10^{-3} \mathrm{moldm}^{-3}$ on ultraviolet light irradiation and dark adaptation at $\mathrm{pH} 8.6$ and at $25^{\circ} \mathrm{C}$.

out at $\mathrm{pH} 8.6$, since it was shown that the most remarkable conformational change of the rose-PGA membrane with $15.5 \mathrm{~mol} \%$ rose groups could be observed by the irradiation at pH 8.6. ${ }^{17}$ Figure 5 shows the increase and recovery cycle of the membrane potential at $c_{1}=1.0 \times 10^{-2} \mathrm{moldm}^{-3}$. It is clear that the membrane potential can be controlled by UV irradiation. It seems, however, that photoinduced change in the membrane potential responds more rapidly than the spectral and conformational changes (Figures 1 (a) and (b)). A similar result was observed with the photoresponsive azo-modified poly(L-glutamic acid) membrane. ${ }^{15}$ As will be noted below, the photoinduced potential change can be ascribed to change in the Donnan potential generated at the interface between the membrane and aqueous solution. It is suggested, therefore, that the photoinduced conformational response at the membrane surface may differ in its kinetics from that in the bulk of the membrane, though this has not yet been clarified.

Figure 6 shows the concentration dependence of the membrane potential of the rosePGA membrane with $15.5 \mathrm{~mol} \%$ rose groups adapted in the dark or irradiated. UV irradiation was shown to induce a positive shift of the potential in wide range of $\mathrm{KCl}$ concentration. The membrane potential in the high 


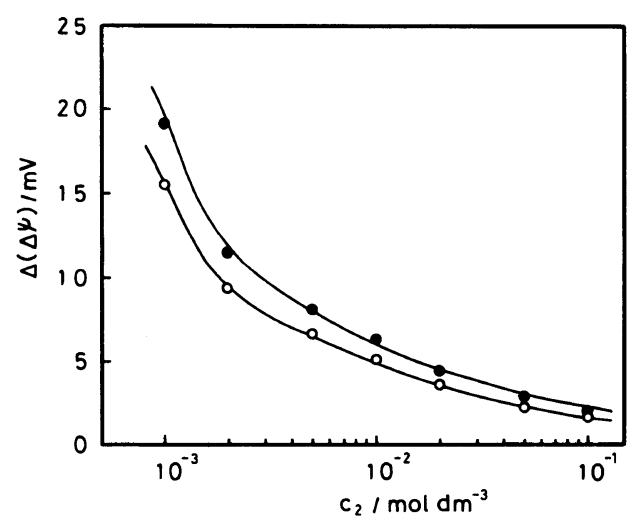

Figure 6. $\mathrm{KCl}$ concentration dependence of membrane potentials of a membrane composed of poly(L-glutamic acid) containing $15.5 \mathrm{~mol} \%$ pararosaniline groups before (-O-) and after (-O-) ultraviolet light irradiation at $25^{\circ} \mathrm{C}$.

external concentration region is generally given as $^{20}$

$$
\begin{aligned}
\Delta(\Delta \psi)= & -\frac{R T}{F}\left[-\left(\frac{\bar{l}_{+}-\bar{l}_{-}}{\bar{l}_{+}+\bar{l}_{-}}\right) \ln r\right. \\
& \left.+\left\{\left(\frac{\bar{l}_{+}-\bar{l}_{-}}{\bar{l}_{+}+\bar{l}_{-}}\right)^{2}-1\right\} \frac{\phi X}{2 K_{ \pm}}\left(\frac{r-1}{r}\right) \frac{1}{c_{2}}\right]
\end{aligned}
$$

where $\bar{l}_{i}$ is the mobility of the $i$ th ion in the membrane, $\phi X$ is the effective (negative) charge density of the membrane, $K_{ \pm}$is the equilibrium partition coefficient, $r=c_{1} / c_{2}$, and $R, T, F$ are commonly used notations. Applying eq 6 to the experimental data in the high concentration region in Figure 6, we can estimate the photoinduced change in the charge density of the membrane, $\phi \mathrm{X} / \mathrm{K}_{ \pm}$, and transport numbers of $\mathrm{K}^{+}$and $\mathrm{Cl}^{-}$in the membrane, $t_{+}=\bar{l}_{+} /\left(\bar{l}_{+}+\bar{l}_{-}\right)$and $t_{-}=\bar{l}_{-} /\left(\bar{l}_{+}+\bar{l}_{-}\right)$, respectively. The result is shown in Table $I$. Irradiation induced an increase in the negative fixed charge density of the membrane, suggesting an increase in the degree of dissociation of the L-glutamic acid moieties in the membrane upon UV irradiation. On the other hand, the transport numbers, $t_{+}$and $t_{-}$, are shown to be independent on UV irradiation. It has been
Table I. Effects of ultraviolet light irradiation on the charge density, $\phi X / K_{ \pm}$, and transport numbers of

$\mathrm{K}^{+}$and $\mathrm{Cl}^{-}\left(t_{+}\right.$and $t_{-}$, respectively) in a membrane composed of poly(L-glutamic acid) containing $15.5 \mathrm{~mol}^{\circ} \%$ pararosaniline groups at $\mathrm{pH} 8.6$ and at $25^{\circ} \mathrm{C}$

\begin{tabular}{lcc}
\hline & In the dark & Irradiation \\
\hline$\phi X / K_{ \pm} / \mathrm{mol} \mathrm{dm}^{-3}$ & $3.96 \times 10^{-3}$ & $5.19 \times 10^{-3}$ \\
$t_{+}$ & 0.511 & 0.511 \\
$t_{-}$ & 0.489 & 0.489 \\
\hline
\end{tabular}

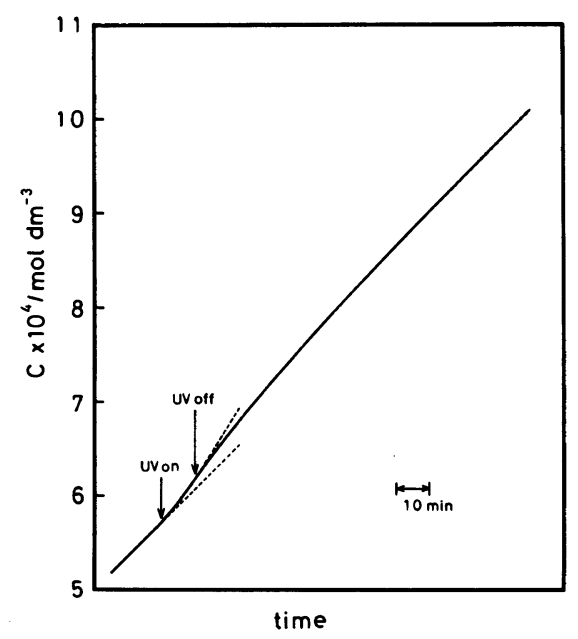

Figure 7. Changes in the permeability of styrene glycol across a membrane composed of poly(L-glutamic acid) containing $15.5 \mathrm{~mol} \%$ pararosaniline groups on ultraviolet light irradiation and dark adaptation at $\mathrm{pH} 8.6$ and at $25^{\circ} \mathrm{C}$.

noted that UV irradiation accelerated the dissociation of the L-glutamic acid groups in the rose-PGA membrane at $\mathrm{pH} 8.6$ resulting from increase in the concentration of $\mathrm{OH}^{-}$via the photodissociation of the rose moieties (Figure 2). It is concluded, therefore, that the photoinduced membrane potential change is the result of Donnan potential change via a change in the fixed charge density of the membrane owing to the induced acid dissociation of the L-glutamic acid moieties with UV irradiation.

\section{Photoinduced Permeability Change of the Rose-} PGA Membrane

Figure 7 shows the permeation curve of 

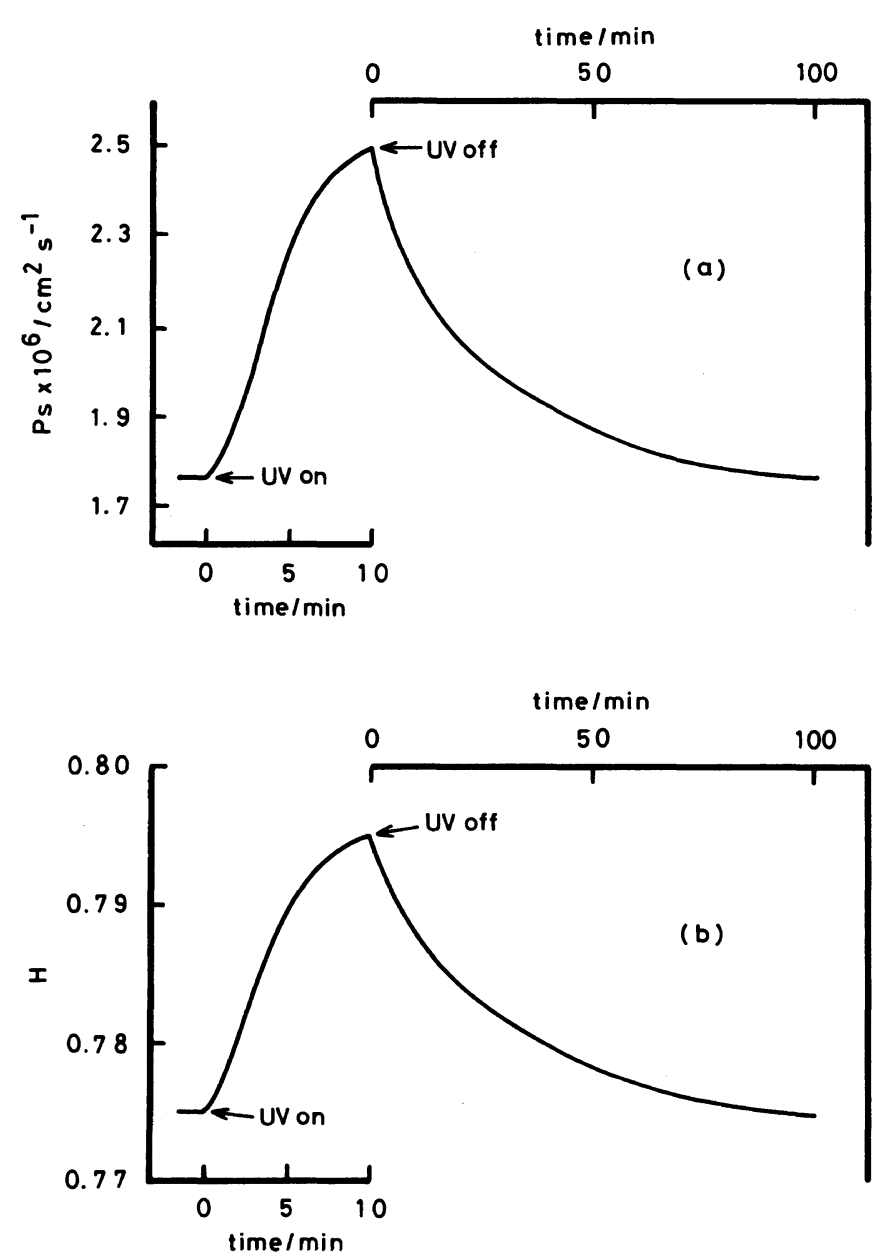

Figure 8. (a) Changes in the permeability coefficient of styrene glycol, $P_{\mathrm{s}}$, across a membrane composed of poly(L-glutamic acid) containing $15.5 \mathrm{~mol} \%$ pararosaniline groups on ultra-violet light irradiation and dark adaptation at $\mathrm{pH} 8.6$ and at $25^{\circ} \mathrm{C}$; (b) changes in the degree of hydration, $\mathrm{H}$, of a membrane composed of poly(L-glutamic acid) containing $15.5 \mathrm{~mol} \%$ pararosaniline groups on ultraviolet light irradiation and dark adaptation at $\mathrm{pH} 8.6$ and at $25^{\circ} \mathrm{C}$.

styrene glycol through the rose-PGA membrane with $15.5 \mathrm{~mol} \%$ of rose moieties at $\mathrm{pH}$ 8.6. It is seen that the permeation amount of styrene glycol increased linearly with time in the dark. Moreover, when the membrane was irradiated, the permeation of the solute immediately increased. The permeation coefficient, $P_{\mathrm{s}}$, was calculated from the slope of the permeation curve in Figure 7. The result is shown as a function of time in Figure 8(a). The value of $P_{\mathrm{s}}$ increased by a factor of 1.43 from
$1.75 \times 10^{-6} \mathrm{~cm}^{2} \mathrm{~s}^{-1}$ to $2.50 \times 10^{-6} \mathrm{~cm}^{2} \mathrm{~s}^{-1}$ by $\mathrm{UV}$ irradiation at $\mathrm{pH}$ 8.6. It is well known that one of the important factors determining the permeability through a polymer membrane is the degree of hydration (swelling) of the membrane. ${ }^{21}$ Figure $8(\mathrm{~b})$ shows the photoinduced change in the degree of hydration of the rosePGA membrane containing $15.5 \mathrm{~mol} \%$ rose groups. As expected, the degree of hydration of the membrane increased on UV irradiation and returned to its original value in the dark. 
One reason for this finding could be an increase in the hydrophilic nature of the membrane resulting from the photoinduced acceleration of the L-glutamic acid dissociation described above. It is also clear from Figure 8 that the photoinduced permeability change was entirely consistent with the change in the degree of hydration of the membrane (Figure 8(b)) and also with the conformational response to light in Figure 1(b). Therefore, it is concluded that the photoinduced increase of the permeability of styrene glycol can be attributed to increase in the degree of hydration of the membrane resulting from conformational change of rose-PGA by UV irradiation.

Acknowledgement. The authors gratefully acknowledge the support of the Japanese Ministry of Education through a Grant-in-Aid for Developmental Science Research.

\section{REFERENCES}

1. J. Anzai, H. Sasaki, A. Ueno, and T. Osa, J. Chem. Soc., Chem. Commun., 1045 (1983).

2. J. Anzai, A. Ueno, H. Sasaki, K. Shimokawa, and T. Osa, Makromol. Chem., Rapid Commun., 4, 731 (1983).

3. S. Kato, M. Aizawa, and S. Suzuki, J. Membrane Sci., 1, 289 (1976).
4. S. Kato, M. Aizawa, and S. Suzuki, J. Membrane Sci., 2, 39 (1977).

5. J. Anzai, H. Sasaki, A. Ueno, and T. Osa, Chem. Lett., 1443 (1985).

6. J. Anzai, Y. Hasebe, A. Ueno, and T. Osa, Kobunshi Ronbunshu, 43, 683 (1986).

7. H. Sasaki, A. Ueno, J. Anzai, and T. Osa, Bull. Chem. Soc. Jpn., 59, 1953 (1986).

8. M. Aizawa, S. Tomono, and S. Suzuki, J. Membrane Sci., 2, 289 (1977).

9. H. Sasaki, A. Ueno, and T. Osa, Chem. Lett., 529 (1987).

10. M. Irie, A. Menju, and K. Hayashi, Nippon Kagaku Kaishi, 227 (1984).

11. K. Ishihara and I. Shinohara, J. Polym. Sci., Polym. Chem. Ed., 22, 515 (1984).

12. K. Ishihara, N. Hamada, S. Kato, and I. Shinohara, J. Polym. Sci., Polym. Chem. Ed., 22, 881 (1984).

13. T. Kinoshita, M. Sato, A. Takizawa, and Y. Tsujita, J. Chem. Soc., Chem. Commun., 929 (1984).

14. A. Takizawa, M. Sato, T. Kinoshita, and Y. Tsujita, Chem. Lett., 1963 (1984).

15. T. Kinoshita, M. Sato, A. Takizawa, and Y. Tsujita, Macromolecules, 19, 51 (1986).

16. T. Kinoshita, M. Sato, A. Takizawa, and Y. Tsujita, J. Am. Chem. Soc., 108, 6399 (1986).

17. M. Sato, T. Kinoshita, A. Takizawa, and Y. Tsujita, Macromolecules, in press.

18. M. Irie, J. Am. Chem. Soc., 105, 2078 (1983).

19. A. A. Frost and R. G. Pearson, "Kinetics and Mechanism," John Wiley \& Sons, Inc., New York, 1961, p 160, Chapter 8.

20. A. Takizawa, Hyomen, 20, 68 (1982).

21. H. Yasuda, C. E. Lamaze, and A. Peterlin, J. Polym. Sci., 9, 1117 (1971). 